\title{
Language Learning Strategies and Its Training Model
}

\author{
Jing Liu \\ School of Foreign Language, Qingdao University of Science and Technology \\ 69 Songling Road, Qingdao 266061, China \\ Tel: 86-532-8872-2236 E-mail: rogerliu99@tom.com
}

The research, a part of the project approved by Shandong Provincial Education Department No.EC201016, is financed by Qingdao University of Science and Technology NO. 09XB07.

\begin{abstract}
This paper summarizes and reviews the literature regarding language learning strategies and it's training model, pointing out the significance of language learning strategies to EFL learners and an applicable and effective language learning strategies training model, which is beneficial both to EFL learners and instructors, is badly needed.
\end{abstract}

Keywords: Language learning strategies, Classification, Training model

\section{Introduction}

According to Oxford (1989), language learning strategies are behaviors or actions which learners use to make language learning more successful, self-directed and enjoyable. And Stern (1983), had noted that learning outcomes are much influenced by learning process, and the learning process is affected by the learners' internal characteristics and learning conditions. So the studies on language learning strategies have been of great significance. Although this area might hold much promise, it is still in its infancy.

\section{Classification of Language Learning Strategies}

Many scholars had attempted to classify learning strategies. Comprehensive classification schemes of learner strategies have been developed to describe the information derived from descriptive studies that seek to chart the subtle permutations and often imprecise definitions of learners' self-reported strategies. Earlier researchers used their own observations to describe language learning strategies, relied on categories derived from research in first language contexts, or developed a comprehensive list of learning strategies derived from many sources. More recently, strategy identification and classification have been data-driven through think-aloud protocol analysis. (Chamot 2004)

\subsection{Wenden's Classification}

Wenden's (1983) research examined the strategies that adult foreign language learners use in order to direct their own learning. Wenden's focus, therefore, is on what O'Malley and Chamot call meta-cognitive strategies. She identifies the following three general categories of self-directing strategies:

(1) Knowing about language and relating to what language and language learning involves;

(2) Planning relating to the 'what' and 'how' of language learning;

(3) Self-evaluation. It relates to progress in learning and learner's responses to the learning experience. Wenden's framework was considered as a basis for the later EFL learner's training.

\subsection{Dansereau's Classification}

Dansereau (1985) draws a distinction between a primary strategy and support strategies, the former is used to directly manage learning materials, and the latter helps to establish an appropriate learning attitude and therefore aids in coping with distractions, fatigue and frustrations. Later Oxford suggested two broad categories paralleling Dansereau's primary strategies and support strategies.

\subsection{Rubin's Classification}

According to the criteria of whether the strategy contributes directly or indirectly to learning, Rubin proposed a classification scheme that subsumes learning strategies under two primary groupings and a number of subgroups. She describes a typology of three major kinds of strategies: learning, (interactive) communication, and social strategies. Learner strategies "contribute to the development of the language system...and affect learning directly" (Rubin 1987:23). Language learning strategies are further categorized in cognitive and meta-cognitive strategies, which directly affect the development of the language system constructed by the learner. Rubin's 
cognitive strategies include: clarification/verification, guessing/inductive inferencing, deductive reasoning, practice (e.g. repetition, rehearsal, experimentation, application of rules, imitation, attention to detail), memorization, and monitoring. Meta-cognitive strategies involve various processes such as planning, prioritizing, setting goals, and self-management. Communication strategies are less directly related to language learning since they focus on the process of participating in a conversation and getting the speaker understood or clarifying his original intention. Social strategies, which contribute indirectly to language learning, are described by Rubin as activities affording them opportunities to be exposed to and practice their knowledge. They include: questions to fellow students/teachers/native speakers, initiating conversations, listening to L2 media etc.

\subsection{Oxford's Classification}

A distinction is drawn between direct and indirect strategies by Oxford (1990). Jones (1998) believes that Oxford has developed a system of language learning strategies that is more comprehensive and detailed than earlier classification models. However, as Oxford herself concedes, there is no agreement on the basic definitions of the terms 'direct' and 'indirect', nor on "exactly what strategies are; how many strategies exist; how they should be defined, demarcated, and categorized".

Direct strategies, which "involve direct learning and use of the subject matter, in this case a new language" are subdivided into three groups: memory strategies, cognitive strategies and compensation strategies; Indirect language learning strategies, which "contribute indirectly but powerfully to learning", are also subdivided into three groups: meta-cognitive strategies, affective strategies and social strategies. According to Oxford (1990), memory strategies such as creating mental linkages and employing actions, aid in entering information into long-term memory and retrieving information when needed for communication. Cognitive strategies, such as analyzing and reasoning, are used for forming and revising internal mental modes and receiving and producing messages in the target language. Compensation strategies, such as guessing unknown words while listening and reading or using circumlocution in speaking and writing, are used by learners when a language task is beyond their reach, to make up for their incompetence in the target language so as to continue the communication. Meta-cognitive strategies help learners to regulate their learning through planning, arranging, focusing, and evaluating their own learning process. Affective strategies enable learners to control feelings such as confidence, motivations, and attitudes related to language learning. Social strategies, such as asking questions and cooperation with others, facilitate interaction with others, often in a discourse situation.

Although many factors might influence the degree to which and the way in which language learners use specific strategies, generally speaking, they will apply all the different strategies depending on their cultural and ethnic background, personality, gender, proficiency, language learning purpose, cognitive style, the task at hand, etc. And all these types of strategies are important to good language learning. Thus, it is acknowledged that an understanding and awareness of learner strategies on the part of both teacher and students may provide valuable insights into the process of language learning. This, in turn, may enable individual learners to adopt or further develop a range of effective language learning strategies, and may encourage teachers to incorporate their active use in regular class. As Oxford (1990) put it, "strategies are especially important for language learning because they are tools for active, self-directed involvement, which is essential for developing communicative competence."

\subsection{O'Malley's Classification}

O'Malley and Chamot's (1990) classification emerged from interviews with experts and novices and theoretical analyses of reading comprehension and problem solving. And language learning strategies are differentiated into the three primary categories cognitive, meta-cognitive and affective or social strategies:

In their opinion, meta-cognitive strategies involve "knowing about learning and controlling learning through planning (including advance organizers, directed attention, functional planning, selective attention and self-management), monitoring (checking, verifying, or correcting one's comprehension or performance in the course of language task) and evaluating the learning activity (checking the outcomes of one's own language learning against a standard after it has been completed)". Cognitive strategies involve the manipulation or transformation of the material to be learned, such as resourcing, repetition, grouping, deduction, imagery, auditory representation, key word method, elaboration, transfer, inferencing, note taking, summarizing, recombination and translation. And Social/affective strategies mainly involve the learner in communicative interaction with another person, for example, when collaborating with peers in problem-solving exercises.

\subsection{Cohen's Classification}

According to Cohen (2000), language learning and language use strategies are defined as processes which are consciously selected by learners. Language learning strategies, which are used with an explicit goal of improving learner knowledge of given language, are composed of cognitive strategies, meta-cognitive strategies, affective 
strategies and social strategies. While language use strategies, which include retrieval strategies, rehearsal strategies, cover strategies, and communication strategies, focus primarily on helping students utilize the language as much as possible. This may result in actions that enhance the learning or use of a second or foreign language, through the storage, retention, recall, and application of information in or about the target language.

Meta-cognitive strategies deal with pre-assessment and preplanning, on-line planning and evaluation, and post-evaluation of language learning activities and of language use events. Such strategies allow learners to control their cognition by coordinating the planning, organizing, and evaluating of the learning process. Cognitive strategies encompass the language learning strategies of identification, grouping, retention, and storage of language material, as well as the language use strategies of retrieval, rehearsal, and comprehension or production of words, phrases, and other elements of the second language. Affective strategies serve to regulate emotions, motivation, and attitudes, for instance, strategies for reduction of anxiety and for self-encouragement. Social strategies include the actions which learners choose to take in order to interact with other learners and with native speakers, such as clarification and cooperation .Retrieval strategies refer to the strategies helping to call up language material from storage, through whatever memory searching strategies the learner can muster, like the keyword mnemonic.Rehearsal strategies stand for strategies for rehearsing target language structures, which are employed for the purpose of practicing the target language structures. Cover strategies are compensatory or coping strategies that learners use to cover their lack of the language competence or create the impression that they have control over material when they do not. Simplification and complexification are typical examples of cover strategies (Cohen, 2000).

\section{Training Model of Language Learning Strategies}

Rubin (1981) claims that the strategies are not the preserve of highly capable individuals, but could be learned by others. O'Malley et al. (1994) also states that the learning strategies of good language learners, once identified and successfully taught to less competent learners, could have considerable potential for enhancing the development of second language skills; and that second language teachers could play an active and valuable role by teaching students how to apply learning strategies to varied language activities and how to extend the strategies to new tasks both in the language classroom and in content areas requiring language skills. With the development of strategy training, researchers have probed and tested various models for strategy training.

\subsection{Pearson \& Dole's Model}

Pearson \& Dole (1987) design one strategy training model for L1 learners. It advocates that teachers first give students the explanation of the benefits of applying a specific strategy and the modeling, which is followed by students transferring the strategy to new environment. Students may better understand the applications of the various strategies if they are first modeled by the teacher and then practiced individually. After some strategies have been introduced and practiced, the teacher can further encourage independent strategy use and promote learners` autonomy. Pearson and Dole's model includes the following sequences (Cohen, 1998):

(1) Introduction to the target strategy through examples. The teacher exposes the students to examples and discusses with them how, when, where and why the strategy is used;

(2) Definition and explanation. The strategy is defined and its application is demonstrated with the teacher modeling;

(3) Guided practice. The teacher and students do exercises together in order that the students can do independent practices;

(4) Independent practices. The students do the same type of exercises independently.

Pearson \& Dole's model cast some lights on learning strategy training, however, this model is narrowed down on one simple strategy or skill, and thus, it's hard to develop students' problem-solving competence in complex and authentic learning tasks.

\subsection{Oxford's Model}

Oxford's Model (1990) has many strong points. It is carried out step by step in the following procedure:

(1) Learners are asked to immerse into an authentic language task without instructional cues;

(2) Suggest and demonstrate other helpful strategies, mentioning the need for greater self-direction and expected benefits, and making sure that the students are aware of the rationale for strategy use;

(3) Allow learners plenty of time to practice the new strategies with language tasks and show how the strategies can be transferred to other tasks;

(4) Provide practice using the techniques with new tasks and allow learners to make choices about the strategies 
they will use to complete the language learning tasks;

(5) Help students understand how to evaluate the success of their strategy use and to gauge their progress as more responsible and self-directed learners.

Generally, this model is flexible in terms of procedure, in other words, each step can be modified or rearranged in different orders for different needs and intentions. But the weak point of this model is it is hard to be inserted into a regular classroom program.

\subsection{Chamot`s Model}

The Cognitive Academic Language Learning Approach (CALLA) is investigated by Chamot and O'Malley. It is designed to develop the academic language skills of the students with limited English proficiency. Since their first proposal of this approach in 1986, Chamot and O'Malley have continuously been working on the model, enlarging and refining it. This model integrates academic language development, content area instruction and explicit instruction in learning strategies for both content and language acquisition. The CALLA (Chamot, 2005; Chamot et al., 1999) model is composed of six steps, namely:

(1) Preparation. In this stage, the teacher identifies students' current learning strategies for familiar tasks, such as recalling their prior knowledge, previewing the key vocabulary and concepts to be introduced to the lesson;

(2) Presentation. In this stage, the teacher models, names, explains new strategy; asks students if and how they have used it, such as selective attention, self-monitoring, inference, elaboration, imagery and note-taking strategies;

(3) Practice. In this stage, the students practice new strategy; in subsequent strategy practice, the teacher fades reminders to encourage independent strategy use by being asked to check their language production, plan to develop an oral or written report or classify concepts;

(4) Evaluation. In this phase, the students evaluate their own strategy use immediately after practice, determining the effectiveness of their own learning by summarizing or giving a self-talk, either cooperatively or individually;

(5) Expansion activities. In this phase, the students transfer the strategies to new tasks, combine strategies into clusters, develop repertoire of preferred strategies and integrate them into their existing knowledge frameworks.

(6) Assessment. In this stage, the teacher assesses the students' use of strategies and impact on performance.

Chamot's model integrates strategy learning into the content-based and academic activities, which reflects the philosophy in language learning and teaching. The CALLA model is recursive rather than linear so that teachers and students always have the option of revisiting prior instructional phases as needed (Chamot, 2005) and useful for language learners of different levels, which has been considered as a guide for implementing a whole-language or language-across-curriculum approach to instruction, and undoubtedly it has been applied in the EFL classroom program.

\subsection{Cohen's model}

Cohen's (1998) Styles and Strategies-Based Instruction Model (SSBI) is a learner-centered approach, which includes both explicit and implicit integration of strategies into the course content. Generally speaking, in a SSBI Model, the teachers usually play the following roles:

(1) Teacher as diagnostician. The teacher helps the students identify current strategies and learning styles

(2) Teacher as language learner. The teacher shares own learning experiences and thinking processes.

(3) Teacher as learner trainer. The teacher trains the students how to use learning strategies.

(4) Teacher as coordinator. The teacher supervises students' study plans and monitors difficulties

(5) Teacher as coach. The teacher provides on going guidance on students' progress.

Comparatively speaking, Cohen's model describes and prescribes what a teacher should do in a regular EFL classroom. It provides more flexibility for teachers to explicitly and implicitly embed the language strategies training into regular classroom program. And it makes more sense in the context of student-centered EFL instruction. Many experimental or non-experimental strategies training researches on cognitive and meta-cognitive strategies training adopt this model.

\subsection{Grenfell and Harris's model}

Grenfell and Harris (1999) developed a model of language learning strategies instruction as the fowling:

(1) Awareness raising. The students complete a task, and then identify the strategies they used.

(2) Modeling. The teacher models, discusses the value of new strategy, makes checklist of strategies for later use. 
(3) General practice. The students practice new strategies with different tasks.

(4) Action planning. The students set goals and choose strategies to attain those goals.

(5) Focused practice. The students carry out action plan using selected strategies; the teacher fades prompts so that students use strategies automatically.

(6) Evaluation. The teacher and students evaluate success of action plan; set new goals; cycle begins again.

In summary, all the above-mentioned models share a number of common features stressing on the importance of developing students' meta-cognitive understanding of the value of learning strategies and it can be facilitated by teacher's demonstration and modeling. Though practicing and evaluating, the strategies get internalized and automatized and then being transferred to solve new tasks.

\section{Conclusion}

Researches into what learners do to solve language learning problems have resulted in the identification of specific strategies and attempts to classify them according to various criteria. Different researchers have labeled different learning behaviors out of different considerations. Although considerable headway has undoubtedly been made, language learning strategies classification systems clearly need further development and standardization. In particular, an applicable and effective language learning strategies training model, which is beneficial both to EFL learners and instructors, is demanded.

\section{References}

Chamot, A.U. \& EI-Dniary, P.B. (1999). Children's learning strategies in immersion classrooms. The Modern Language Journal, 83(3), 319-341.

Chamot, A.U. (2004). Issues in Language Learning Strategy Research and Teaching. Electronic Journal of Foreign Language Teaching 1/1:14-26.

Chamot, A.U. (2005). The Cognitive Academic Language Learning Approach (CALLA): An update. In P.A. Richard-Amato \& M.A. Snow (Eds.), Academic success for English language learners: Strategies for K-12 mainstream teachers (pp. 87-101). White Plains, NY: Longman.

Cohen, A.D. (1998, 2000). Strategies in Learning and Using a Second Language. Addison Wesley Longman Limited.

Dansereau, D F. (1985). Learning Strategy Research. In J.W. Segal, S.F. Chipman and R. Glaser (Eds.), Thinking and Learning Skills. Hillsdale, N J Erlbaum, (1):9-39.

Grenfell, M. \& Harris, V. (1999). Modern languages and learning strategies: In theory and practice. London: Routledge.

Jones,R.(1998). Two faces of AIDS in Hong Kong: Culture and the construction of the AIDS celebrity. Discourse and Society 9/3:353-382.

O’Malley et al. (1985a). Learning Strategies Used by Beginning and Intermediate ESL Students. In Language Learning.

O’Malley, J.M. \& A.U. Chamot. (1990).Learning strategies in Second Language Acquisition. Cambridge: Cambridge University Press.

O’Malley M \& A U Chamot. (1994). The CALLA handbook: implementing the cognitive academic language learning approach.N.J: Addison-Wesley, Reading MA. Harlow, England: Longman.

Oxford R\& M Nyikos. (1989). Variables Affecting Choice of Language Learning Strategies by University Students.The Modern Language Journal, (3):291-299.

Oxford, R. (1990). Language Learning Strategies: What Every Teacher Should Know. Rowley, Mass: Newbury House, 284-297.

Person P D\&J A Dole. (1987). Explicit Comprehension Instruction: A Review of Research and a New Conceptualization of Learning. Elementary School Journal.

Rubin. J. (1981). Study of Cognitive Processes in Second Language Learning.Applied Linguistics (2):117-131.

Rubin. (1987). Learner Strategies: Theoretical Assumptions, Research History and Typology. In Wenden \& Rubin (Eds.).

Stern, H. (1983). Fundamental Concepts of Language Teaching. Oxford: Oxford University Press.

Wenden,A \& J.Rubin.(1987). Learner Strategies in Language Learning. Englewood Cliffs, NJ: Prentice Hall. 